\title{
Tensile Properties and Fracture of Viscose Yarn Under High Speed Impact
}

\author{
F. Marques ${ }^{1}$, E. Cabeço Silva ${ }^{1}$, M. José Abreu${ }^{1}$, Jean-Yves Drean ${ }^{2}$ \\ ${ }^{1}$ Departamento de Engenharia Têxtil, Escola de Engenharia da Universidade do Minho \\ 4800 - 058 Guimarães, Portugal \\ ${ }^{2}$ Ecole Nationale Supérieure des Industries Textiles de Mulhouse, 11, rue Alfred Werner, 68093 \\ Mulhouse Cedex, France
}

Keywords: HSD, strain rate, viscose multifilament yarn, tensile properties, granular fracture

\begin{abstract}
In order to ensure an acceptable quality even at the highest spinning or weaving speeds, tensile instruments and testing conditions have to be improved. Therefore, a new high-speed dynamometer and a new method to subject yarns at strain rates similar to those found in current textile operations have been developed. This high-speed dynamometer has then been used to investigate the influence of high strain rates on tensile properties and fracture morphology of a technical viscose multifilament yarn.
\end{abstract}

\section{Introduction}

The yarn in many textile operations is subjected to sudden stresses at high stress induced speeds, for instance during the insertion of weft, whether by projectile or air jet, the yarn has to stand accelerations many thousands times greater than that due to gravity [1]. The conventional standard tensile testing cannot cope with such stresses because the maximum speed only reaches a few millimetres per second.

The unique available commercial exception is Uster Tensojet. However, this high-speed dynamometer shows some important shortcomings. In fact, Tensojet measures only tenacity and extension at break, tensile tests are limited to spun yarns, gauge length can only be set at $0.5 \mathrm{~m}$ and speeds are fixed at 50,100, 200 and $400 \mathrm{~m} / \mathrm{min}$.

In order to overcome such restrictions, a new high-speed dynamometer (HSD) have been developed, which adds speed up to $2400 \mathrm{~m} / \mathrm{min}$, tests both filament and spun yarns, gauge length can be set from 0.25 to $1.40 \mathrm{~m}$ and measures a wide range of tensile properties [2]. The global measurement system is composed of a computer, the high-speed dynamometer itself, a charge amplifier and an oscilloscope (Fig. 1).

Higher speeds produce higher strain rates and it is well known that the strain rate increasing alters the time to break during loading and influence the yarn tenacity and breaking extension. Previous studies on filament yarns have shown that a rapid straining results usually in a higher breaking load $[3,4]$. Nevertheless, in many of those investigations the test length of the yarn under examination does not conform to that required by standard tensile test.

Thus, the purpose of this paper is to show how strain rate affects tensile properties, but assuring the following conditions [5]. First of all, the yarn test length is always constant and conforms to standard test. Secondly, the breakage of the yarn only takes place when the required acceleration of the yarn has been completed.

The importance of yarn strength is well recognised, but until recently not much was known about the way in which filaments or fibres break. The scanning electron microscopic has allowed investigating the influence of strain rate on the fracture morphology of viscose filament yarn. The understanding of the way in which filaments are breaking down under tensile load can be a great help to the thinking of the product engineer and even an important tool in the analysis of the pathology of the product failure. 